\title{
Formas de organización política territorial y disputas electorales municipales en Santiago del Estero (2005-2018). Las redes partidarias y sus entornos desde una perspectiva socio cultural de la política
}

\section{Forms of territorial political organization and municipal electoral disputes in Santiago del Estero (2005-2018). Party networks and their environments from a socio-cultural} perspective of politics

\section{Hernán Campos}

campos_hernan@hotmail.com

CONICET-Instituto de Estudios para el Desarrollo Social. Universidad Nacional de Santiago del Estero, Argentina

\section{Recepción: 01 Marzo 2021}

Aprobación: 01 Octubre 2021

Publicación: 01 Diciembre 2021

Cita sugerida: Campos, H. (2021). Formas de organización política territorial y disputas electorales municipales en Santiago del Estero (2005-2018). Las redes partidarias y sus entornos desde una perspectiva socio cultural de la política. Cuestiones de Sociología, 25, e128. https://doi.org/10.24215/23468904e128
Resumen: El artículo se propone estudiar la relación entre la organización política de los partidos a nivel territorial (las redes partidarias municipales) y las disputas electorales en la provincia de Santiago del Estero (entre 2005 y 2018), para aprehender la interacción entre el sistema político provincial y las redes políticas municipales. Los resultados muestran que el oficialismo provincial en Santiago del Estero construye predominio político, sin embargo, convive con un proceso de disputa política electoral a nivel municipal. En el caso estudiado, el Frente Cívico, predominante a nivel provincial, funciona a nivel municipal como sistema que contiene oficialismo y oposición.

Palabras clave: Formas de organización territorial, Redes partidarias, Elecciones municipales.

Abstract: The article proposes to study the relationship between the political organization of the parties at the territorial level (the municipal party networks) and the electoral disputes in the province of Santiago del Estero (between 2005 and 2018), to apprehend the interaction between the provincial political system and municipal political networks. The results show that the ruling party in Santiago del Estero builds political dominance, however, it coexists with a process of electoral political dispute at the municipal level. In the case studied, the Civic Front, predominant at the provincial level, functions at the municipal level as a system that contains both government and opposition.

Keywords: Forms of territorial organization, Party networks, Local elections. 


\section{Introducción}

En un contexto de fragmentación del sistema de partidos nacionales y de fortaleza de los liderazgos provinciales (Calvo y Escolar, 2005; Leiras, 2007), las experiencias provinciales de coaliciones o frentes partidarios que se vuelven predominantes, como el Frente Cívico en Santiago del Estero, han comenzado a ser estudiadas (Ortiz de Rozas, 2014 y 2011; Abdulhadi, 2016; Quilici, 2017; Campos, 2018, Maidana, 2016; Vaca Ávila, 2017). La literatura se enfocó primordialmente en las relaciones de las fuerzas provinciales con los gobiernos nacionales y con movimientos sociales. Sin embargo, los estudios sobre la relación de las formas de organización partidaria provincial con las disputas electorales municipales es un tema a seguir indagando. ${ }^{1}$

El artículo se propone estudiar la relación entre la organización política de los partidos a nivel territorial (las redes partidarias municipales) y las disputas electorales en la provincia de Santiago del Estero ${ }^{2}$ (entre 2005 y 2018), para aprehender la interacción (influencia de un nivel en otro, variación, alineamiento) entre el sistema político provincial y las redes políticas municipales.

Los resultados muestran que el oficialismo provincial en Santiago del Estero construye predominio político; sin embargo, convive con un proceso de disputa política electoral a nivel municipal. En el caso estudiado, el Frente Cívico, predominante a nivel provincial, funciona a nivel municipal como sistema que contiene oficialismo y oposición (Campos, 2021).

En términos teóricos, la hipótesis es que, en el estudio de la política subnacional, el foco en la política municipal permite entender tanto las bases de poder como la heterogeneidad de las fuerzas políticas predominantes a nivel provincial. $^{3}$

El análisis en términos de redes partidarias, y las nociones de medio social partidario contribuyen a pensar la relación partido y sociedad (Sawicki, 2020).

\footnotetext{
"Uno de los desafíos de una verdadera sociología de los partidos implica que las estrategias y modos de hacer de los emprendedores políticos no pueden explicarse únicamente como el producto de una búsqueda racional y sistemática de poder, sino que están condicionados por marcos cognitivos y normativos objetivados en las reglas y un lenguaje que puede estar relacionado con una cultura partidaria. Estas reglas son vinculantes para ellos, restringen al mismo tiempo que hacen que sus acciones sean aceptables y comprensibles" (Sawicki, 2020, p. 152)
}

Los hallazgos construidos surgieron de las descripciones de las prácticas de las redes políticas ${ }^{4}$ en las elecciones municipales de los años 2006, 2010, 2014, 2018 y del análisis comparativo, por medio de la indagación con prosopografía, de las agrupaciones y actores políticos que ganaron y perdieron en las elecciones municipales 2006, 2010, 2014 y la de agosto de 2018.5

Entre los hallazgos de la indagación podemos destacar: el carácter predominante del Frente Cívico como principal fuerza política en las elecciones municipales. Y en relación a lo dicho anteriormente, las principales disputas electorales municipales se suceden dentro de la misma alianza política provincial, entre redes peronistas y radicales. 


\section{Elementos teóricos y contextuales que explican el predominio del oficialismo provincial}

\subsection{Pensar desde una perspectiva socio cultural de la politica}

La problemática se inscribe en una línea de la sociología política que aborda las redes partidarias y sus entornos partidarios (Sawicki, 2011), para comprender cómo la representación se relaciona con los anclajes sociales de los partidos. ${ }^{6}$ El enfoque socio político contribuye a estudiar la relación entre la dinámica provincial y nacional desde las prácticas políticas de los actores y el vínculo de los partidos con sus contextos sociales.

En relación con el concepto de entornos partidarios de Sawicki (2011), Vommaro nos propone que los mundos sociales de pertenencia son así anclajes sociales que proveen marcos de sentido, a la vez condicionamientos y recursos para la acción de los miembros de un partido (Vommaro, 2017, p. 40). ${ }^{7}$

El concepto de mundos sociales de pertenencias nos ayuda a pensar sobre jerarquías políticas dentro de la política provincial.

La noción de jerarquía permite explorar los diferentes modos de construir y reproducir un orden legítimo en el que se establecen relaciones entre las cosas y las personas, por las cuales se establecen posiciones o recursos desiguales (Landau, 2019). Siguiendo los aportes de Landau, esas jerarquías deben ser abordadas en sus tres dimensiones: social, institucional partidario y agencial (Landau, 2019, p. 74).

En base a los aportes de Vommaro y Landau, es necesario trabajar desde la categoría de organización territorial (Campos, 2018) para indagar sobre las redes partidarias, las prácticas políticas y las disputas en un contexto municipal o de la política local.

Las formas de organización territorial (Campos, 2018) suponen un conjunto de prácticas vinculadas al sostenimiento de la presencia de las redes partidarias dentro de un barrio, una comunidad, una localidad. Ellas comprenden tareas concretas y funciones específicas distribuidas según la posición que ocupan los distintos miembros dentro de la jerarquía de la red política o de la división del trabajo político. Estas tareas y funciones se inscriben dentro de la tradición política en la que fueron socializados los dirigentes de la organización, imprimiendo una determinada sensibilidad política que se moviliza en la relación con los sectores sociales y sus demandas. El peronismo y el radicalismo, han sido las tradiciones políticas más influyentes en la configuración de una forma de politicidad (Merklen, 2005), basada en una determinada forma de trabajo politico $^{8}$ (Campos y Schnyder, 2016), entendiéndose este último como la actividad que incluye una inversión de su capacidad productiva ("poner el cuerpo" o "dedicarle tiempo") y que puede implicar una retribución de capital económico, político o social.

La organización territorial también supone, por un lado, la construcción de la representación política entre dirigentes, militantes y vecinos del barrio o de una comunidad y, por otro lado, de la configuración de redes partidarias que gestionan políticas sociales para la implementación en el territorio y la capacidad 
de autogestión para acumular capital económico, y transferir como recurso material, en pos del despliegue y la permanencia de la organización política.

Por último, cabe destacar que las formas de organización territorial de las redes partidarias son sensibles a los "juegos de escalas” (Ortiz de Rozas, 2014). Las redes partidarias "articulan” (Campos, 2018) con actores políticos del nivel local, provincial y nacional (Frederic, 2004; Campos, 2021). Esto se verá reflejado en el apartado 3.

\subsection{Caracterizar al Frente Cívico dentro del campo politico}

Para contextualizar la posición que ocupa el oficialismo en Santiago del Estero, es menester explicitar que, desde el retorno a la democracia en 1983, siempre triunfó el oficialismo provincial, el peronismo hasta el 2004 y luego el Frente Cívico. ${ }^{9}$ Solo hubo cambio de un mayoritario porcentaje del elenco gobernante al finalizar las dos intervenciones federales, en 1994 y 2004 respectivamente.

El oficialismo provincial llegó al gobierno luego de la Intervención Federal de abril de 2004. Con Gerardo Zamora como gobernador, significó el final del predominio del PJ juarista, el inicio de una nueva fuerza política predominante basada en la concertación entre radicales, peronistas y otros partidos y movimientos sociales, y de la inscripción dentro de la transversalidad impulsada por el entonces presidente Néstor Kirchner (Campos, 2018).

\section{Gráfico $\mathrm{N}^{\circ} 1$}

Resultados electorales para Gobernador. Comparando la perfomance del Frente Cívico con la segunda fuerza.

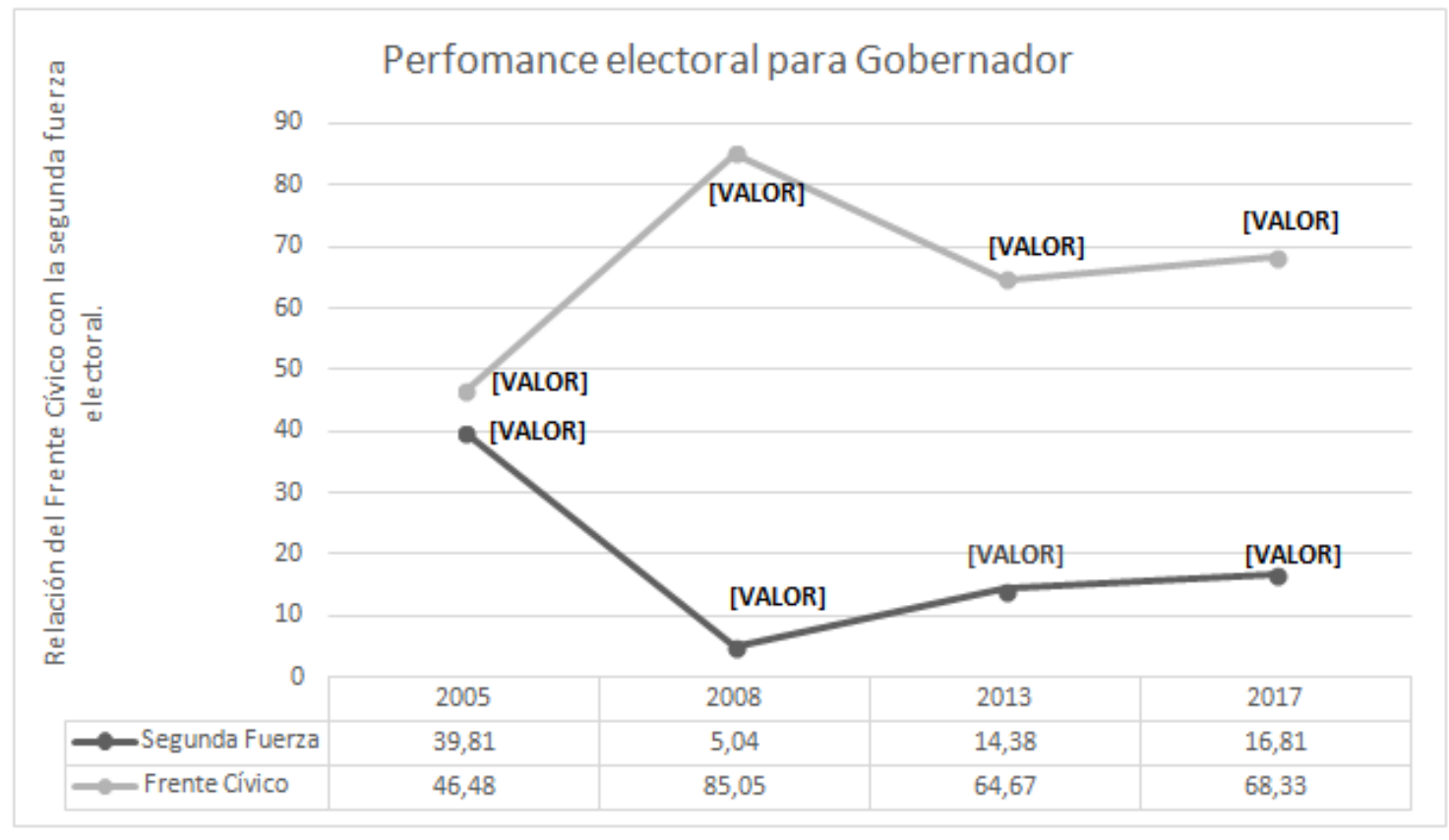

Fuente: Elaboración propia en base a resultados oficiales.

La legitimidad del Frente Cívico se cristaliza en las mayorías que cosechó desde su primera contienda electoral. En febrero de 2005 obtuvo la gobernación con el 46,5\% de los votos, frente al 39,8 \% del PJ que llevaba como candidato al exfuncionario menemista "Pepe" Figueroa. En octubre de ese mismo año, el Frente Cívico obtuvo las tres bancas en juego para diputado nacional con el 
$71,05 \%$ de los votos. La segunda fuerza fue el diezmado e intervenido PJ con el $17,22 \%$ de los votos.

El Frente Cívico ganó las elecciones legislativas nacionales del año 2007; obtuvo las cuatro bancas de diputados en juego $(48,60 \%)$ y dos de senadores (50,44 \%). La banca de Senador restante la ganó el espacio conducido por "Chabay" Ruiz, el Movimiento Viable con el 9,98 \%. El Frente para la Victoria se impuso en las elecciones presidenciales en la provincia con el 79,48 \% de los votos. Allí, contó con el apoyo del gobierno provincial del Frente Cívico, el Movimiento Santiago Viable, el Frente para la Victoria y el Frente Justicialista para la Victoria.

En el año 2008, el Frente Cívico se impuso en las elecciones para gobernador con el $85,3 \%$ de los votos, de igual modo que en las elecciones a diputados provinciales y en las de comisionados municipales. En 2009 obtuvo la totalidad de las bancas de diputados nacionales: en esas elecciones eran tres.

En 2011, el Frente Cívico obtuvo las cuatro bancas para diputados nacionales con el 70,67 \% de los votos, y en la categoría de presidente- vicepresidente, el Frente para la Victoria obtuvo $82,11 \%$.

En 2013, Claudia Ledesma Abdala de Zamora ${ }^{10}$, después del frustrado intento de postulación de Gerardo Zamora, se consagró gobernadora de la Provincia. ${ }^{11}$ En el mismo año, tres bancas en juego para Senadores fueron para la coalición predominante que obtuvo la totalidad (los senadores Daniel A. Brue ${ }^{12}$ y Ada Iturrez de Cappellini y, sumando al Frente Popular de Gerardo Montenegro ${ }^{13}$ que obtuvo la banca por la minoría, pero formando parte de la coalición de gobierno provincial), como así también las tres bancas de Diputados Nacionales: Cristian Oliva, Norma Abdala de Matarazzo y Manuel H. Juárez.

Para las elecciones a Diputados Nacionales, el Frente Cívico obtuvo el 77\% y la segunda fuerza, el Frente Progresista Cívico y Social apenas pudo alcanzar el 14,03\%. En cuanto a la elección de Senadores en donde el oficialismo se había dividido con el propósito de alcanzar las tres bancas en juego, el Frente Cívico alcanzó el 48\% mientras que el Frente Popular llegó al 29,01\%.

En las elecciones nacionales del 2015, que en la provincia se eligieron diputados nacionales y presidente de la República, el Frente Cívico obtuvo tres diputados nacionales con el 65,6\% de los votos, y Unidos por una Nueva Alternativa obtuvo la cuarta banca con el 19,20\%. En esas elecciones, en la fórmula presidencial, el Frente para la Victoria había obtenido en octubre el $62 \%$ de los votos, mientras que Cambiemos, apenas había alcanzado el 14\%.

En las elecciones nacionales del 2017, en donde Gerardo Zamora se consagró gobernador por tercera vez, el Frente Cívico obtuvo casi el $70 \%$ de los votos, logrando las tres bancas de diputados nacionales en juego. ${ }^{14}$

\subsection{Las redes politicas del Frente Civico}

El Frente Cívico se conforma por redes peronistas y radicales que gobiernan desde el año 2005 y que se sostuvo en el tiempo, con una forma de organización territorial coherente. Por supuesto, con la particularidad de una fuerza política que contiene a dos identificaciones partidarias como el peronismo y el radicalismo. 
La forma de organización territorial del Frente Cívico se caracteriza por construir su base de electores por medio de la estrategia de formar Unidades Básicas o Comités y contener dentro de su estructura al sector gremial, compuesto en su mayoría por representantes de los empleados públicos reunidos en la Central General de Trabajadores (CGT).

El Frente Cívico tiene una fuerte implantación territorial y una organización sostenida en un conjunto de redes de interdependencia, tanto barriales como locales. Cuatro estratos podían ser identificados en su interior: los militantes barriales, los dirigentes territoriales que "tienen” sus unidades básicas o Comités, los dirigentes intermedios -intendentes, comisionados municipales, concejales, diputados provinciales, diputados o senadores nacionales- y, en la cúspide, el líder principal, Gerardo Zamora. Es a través de estas redes que el Frente Cívico pone en circulación los recursos públicos bajo su control, y regula el acceso de los sectores populares a los mismos convirtiendo a los dirigentes territoriales como mediadores de las necesidades o demandas de los militantes o adherentes. Las unidades básicas o los comités son unidades ejecutoras de las políticas sociales nacionales y provinciales. Son, a la vez, unidades de recolección de información para la distribución de recursos públicos. Y en períodos electorales, son la base de la logística del proselitismo territorial.

Como se observa en el siguiente cuadro elaborado en base a observaciones y entrevistas, al interior del Frente Cívico existe una división del trabajo político (Hurtado Arroba, Paladino y Vommaro, 2018) por el cual militantes de base, referentes barriales y dirigentes asumían tareas partidarias de distinta responsabilidad. Actividades que podían ser desarrolladas después de la jornada laboral o, en el caso de quienes aún no tenían un empleo, pero aspiraban a conseguirlo a través de su trabajo para el partido, podía ser una ocupación de tiempo completo.

\section{Cuadro $\mathrm{N}^{\circ} 1$}

\begin{tabular}{|c|c|c|c|}
\hline \multicolumn{4}{|c|}{ Actores de la Organización Territorial del Frente Cívico } \\
\hline & Dirigentes & Referentes barriales & Militantes de base \\
\hline $\begin{array}{c}\text { Tipos de } \\
\text { tareas }\end{array}$ & $\begin{array}{l}\text { Afiliar. } \\
\text { Crear Unidades } \\
\text { Básicas o comités. } \\
\text { Aglutinar referentes } \\
\text { barriales en sus } \\
\text { Unidades Básicas o } \\
\text { comités. } \\
\text { Gestionar recursos } \\
\text { para sus referentes } \\
\text { barriales. } \\
\text { Movilizar referentes } \\
\text { barriales y sus } \\
\text { Unidades Básicas. }\end{array}$ & $\begin{array}{l}\text { Afiliar. } \\
\text { Crear Unidades Básicas o } \\
\text { comités. } \\
\text { Gestionar recursos para sus } \\
\text { Unidades Básicas o comités y } \\
\text { sus adherentes. } \\
\text { Relevamientos barriales. } \\
\text { Distribución de recursos públicos } \\
\text { Movilizar militantes. }\end{array}$ & $\begin{array}{l}\text { Afiliar. } \\
\text { Asistir reuniones, actos, } \\
\text { movilizaciones. } \\
\text { Trabajo social en } \\
\text { territorio. }\end{array}$ \\
\hline $\begin{array}{c}\text { Tipos de } \\
\text { recompensas }\end{array}$ & $\begin{array}{l}\text { Candidatura } \\
\text { política. } \\
\text { Acceso a cargos } \\
\text { directivos. } \\
\text { Acceso a recursos } \\
\text { públicos para sus } \\
\text { redes políticas. }\end{array}$ & $\begin{array}{l}\text { Acceso a mayores recursos } \\
\text { públicos para sus Unidades } \\
\text { básicas o comités y adherentes. } \\
\text { Acceso a cargos en la } \\
\text { administración pública nacional, } \\
\text { provincial o municipal. }\end{array}$ & $\begin{array}{l}\text { Asignación de un plan } \\
\text { social. } \\
\text { adjudicación de una } \\
\text { vivienda social o de un } \\
\text { puesto laboral en la } \\
\text { Administración Pública. }\end{array}$ \\
\hline
\end{tabular}


La organización territorial con sus tipos de tareas y recompensas a sus miembros-principio que contribuye a la regulación de las jerarquías intrapartidarias y a la distribución de recursos públicos entre sus miembros- hace que el Frente Cívico fuera espacios de sociabilidad donde se configura la politicidad de los sectores populares y los apoyos electorales.

En el siguiente apartado se presenta una descripción de las redes partidarias en procesos electorales municipales. Prestando atención en ciertas rupturas y continuidades, que serán los hallazgos de este trabajo.

\section{Las redes partidarias en las elecciones municipales de la provincia}

Saliendo de una escuela del municipio de Fernández, luego de la derrota electoral de la Diputada Nacional del PJ- Frente Cívico, Norma Abdala de Matarazzo, con el conteo de los votos y en medio de gritos y festejos, un joven militante de Fernández sostuvo "creo que los viejos del PJ deberían darse cuenta que tienen el ciclo cumplido". En las elecciones municipales de 2018 se consolidó un proceso de transformación dentro del Frente Cívico que generó recambios de gestiones municipales. Cuando se analiza el período 2006-2018, hubo una pérdida de bases territoriales del PJ, que se materializó en las elecciones municipales de 2014 y se consolidó en el 2018.

El cambio de gestiones municipales y la pérdida de organización territorial del PJ expresa que:

1. el agotamiento de las gestiones municipales con varios mandatos consecutivos de la misma facción política, no se manifiesta en un cambio de las formas territoriales de representación política. Esta, es una construcción socio histórica basada en redes de sociabilidad e intercambio.

2. El crecimiento de las redes radicales $\mathrm{u}$ otros grupos no institucionalizados del PJ en los años de gobierno provincial del Frente Cívico se expresó en un cambio de perfil de los intendentes electos.

Las elecciones municipales son un proceso, son la cristalización de correlaciones de fuerzas. Enhebrando un poco más, los comicios no se definen en el día en que se emite el voto o en la misma acción de votar. Las redes políticas electorales son la estructura, construida socialmente, en donde intervienen recursos electorales, económicos, políticos, entre otros y que posibilitan una acumulación de apoyo electoral fundamental para ganar una elección. Siguiendo a Palmeira (2003, p. 42), las elecciones y la práctica de votar no se explica por decisiones individuales, sino por redes de relaciones personales.

Por proceso nos referimos a la logística de traslado y movilización de electores, los recursos económicos para obtener el combustible, los vehículos, los alimentos, los pasajes de colectivos interurbanos, la organización de los fiscales de mesa, los fiscales generales y equipo jurídico, la Unidad Básica o Comité central en donde se coordina todo lo señalado anteriormente y en donde se lleva adelante el punteo del padrón electoral, para conocer con cierto grado de 
precisión la perfomance electoral de los frentes políticos. En este sentido, el crecimiento de la facción radical del Frente Cívico en las elecciones del 2014 tiene respuesta en el papel que jugó el Ministro provincial Luis Gelid desde el Ministerio de la Producción. Consolidó relaciones institucionales y políticas con ministerios nacionales (principalmente el Ministerio de Agricultura de la Nación) y con actores políticos nacionales del gobierno kirchnerista. Así, pudieron dar capacidad de representación y bases de sustentación a los dirigentes locales de la facción radical del Frente Cívico.

"las Agencias de Desarrollo, que pertenecen al Ministerio de Producción de la
provincia y que tenemos contacto directo con productores y campesinos, son nuestras
unidades básicas. Desde abi bajamos proyectos para nuestros dirigentes y ellos trabajan
el territorio generando soluciones. También tenemos vínculo con el Ministerio de
Desarrollo Social de la Provincia en donde gestionamos viviendas de erradicación
rancho, una fuerte demanda de los sectores populares y damos respuestas inmediatas a
un problema real, como es la vivienda" (entrevista a un funcionario municipal de la
facción radical del Frente Cívico durante la campaña electoral del 2014).

Como relata el entrevistado, también hay que tomar nota de la importancia del Ministerio de Desarrollo Social de la provincia, primero con el ministro Martínez y luego con el ex vice gobernador y actual ministro Ángel Niccolai, como potenciador de organización territorial en el interior a través de las gestiones de las viviendas rurales, núcleos húmedos, aljibes y de otras políticas públicas con receptividad en los sectores populares.

Para las elecciones municipales 2018, se consolidaron las redes políticas conducidas por intendentes de procedencia radical. En un contexto provincial de alianzas y articulaciones entre dirigentes, diferentes a las del 2014. Luis Gelid, principal constructor de alianzas con actores locales y generador de capital político (desde recursos para la campaña hasta gestor de programas sociales o productivos para los gobiernos locales), se alejó en el 2017 como Ministro de la Producción y de la función que antes se mencionó. En ese panorama, Gerardo Zamora consolidó el vínculo directo con los intendentes, y la participación de todos los ministros radicales en distintas localidades como "responsables políticos" de las acciones de los intendentes. Insistiendo, la centralización la construye el gobernador Zamora, por otro lado, la descentraliza de modo organizado y territorializado en sus distintos ministros y secretarios. En entrevista con un ministro provincial identificado con el radicalismo señaló "yo tengo que dar la cara por Forres, Fernández y Beltrán. Todo lo que son los armados en esos municipios estoy yo al frente. Si ganan los nuestros, gano yo; si pierden los nuestros, al otro día tengo que dar la cara”.

\section{4. "Derrotas que duelen" y "triunfos para seguir" en las elecciones 2018}

"Derrotas que duelen" dijo un dirigente peronista luego de conocerse los fracasos electorales de la diputada nacional del PJ Frente Cívico, Norma Abdala de Matarazzo en el municipio Fernández; de la derrota por diferencia de $40 \%$ de la red política de la senadora nacional Ada Iturrez de Cappellini en la ciudad de Ojo de Agua; de la pérdida de la conducción de municipios con peso institucional como Añatuya y Monte Quemado, ambas de segunda categoría. 
"No tenemos nada. Tenemos que esperar hasta el 2022 para volver a rearmarnos, pero lo cierto es que quedamos muy mal en la construcción política en el interior. Nos ganaron pendejos o gente que antes no nos podían ni arrimarnos. Pero bueno, esto es política" (entrevista a referente territorial del PJ, el 13 de Agosto de 2018).

“(...) los municipios del norte de la provincia era un bastión nuestro, del peronismo, y la verdad que ver perder a Bochi Chamorro en Campo Gallo, a Hazam en Monte Quemado duele mucho porque se diluye parte de nuestra historia. Hazam fue seis veces intendente de Monte Quemado y Bochi también. Historia viva..." (entrevista a dirigente peronista, el 13 de Agosto de 2018).

Esta consolidación del proceso de pérdida de municipios peronistas que se viene advirtiendo desde el 2014, es una evidencia empírica resultante de las construcciones electorales de los principales actores políticos provinciales, de los recambios generacionales y de los procesamientos de las redes políticas.

Marcela Mansilla, intendenta electa de las redes que provienen del radicalismo, es una de las tres mujeres intendentas ${ }^{15}$ y que tuvo como desafío consolidar la gestión municipal en contextos difíciles ante la implementación del ajuste neoliberal que condujo Mauricio Macri (2015-2019). Estos procesos regionales o nacionales, tienen impacto en la política local. En una conversación con el marido de Marcela y actual diputado provincial, Juan Sequeira, este señaló conocer que la gente apenas llega para comer. En sus visitas "al campo" para la campaña electoral, las familias que viven gracias a las políticas sociales, y que con el gobierno de Macri, "me cuentan que no cenan porque no tienen plata para el guiso".

La consolidación de un proceso de desposesión de derechos sociales, y de vaciamiento de recursos para los municipios, serán desafíos para los gobiernos locales, gestionar, de administrar y de "hacer política" en sus territorios.

Lelo Bitar, intendente re electo en el municipio de Ojo de Agua, que se enfrentó por segunda vez con la red política de la senadora nacional Iturrez de Cappellini, recorría en la caravana del triunfo del 12 de agosto sosteniendo que la elección fue un plebiscito, y que significó un "apoyo" para su gestión iniciada en 2014. En días posteriores, y de manera analítica, sostenía que las elecciones 2018 configuraban la consolidación de dirigentes y redes políticas que vienen de otras experiencias de conducción, diferentes a las del PJ juarista de los años 80 y 90 .

En el cuadro $\mathrm{N}^{\circ} 1$ vemos el predominio electoral 2006-2018 del Frente Cívico en donde gobierna en todos los distritos menos en La Banda. Los cuadros también expresan, por un lado, el desplazamiento del apoyo electoral de una facción del Frente Cívico hacia otra: del peronismo al radicalismo. Insistiendo, hasta el 2014 las redes políticas del PJ del Frente Cívico eran predominantes. Las elecciones municipales del 2014 marcaron un cambio en el dominio y la superioridad de las redes políticas radicales del Frente Cívico. 


\section{Cuadro $\mathrm{N}^{\circ} 1$}

Redes partidarias de intendentes electos de la provincia entre 2006 y 2018.

\begin{tabular}{|l|l|l|l|l|l|l|l|}
\hline & $\begin{array}{l}\text { PJ del } \\
\text { Frente } \\
\text { Cívico }\end{array}$ & $\begin{array}{l}\text { Radicales } \\
\text { y aliados } \\
\text { del Frente } \\
\text { Cívico }\end{array}$ & $\begin{array}{l}\text { Movimiento } \\
\text { Viable }\end{array}$ & $\begin{array}{l}\text { UCR- } \\
\text { Cambiemos }\end{array}$ & $\begin{array}{l}\text { Peronismo } \\
\text { no } \\
\text { oficialista }\end{array}$ & $\begin{array}{l}\text { Frente } \\
\text { Renovador }\end{array}$ & Totales \\
\hline 2006 & $61 \%$ & $36 \%$ & $3 \%$ & $0 \%$ & $0 \%$ & - & $100 \%$ \\
\hline 2010 & $58 \%$ & $33 \%$ & $3 \%$ & $3 \%$ & $3 \%$ & - & $100 \%$ \\
\hline 2014 & $29 \%$ & $62 \%$ & $3 \%$ & $3 \%$ & $3 \%$ & - & $100 \%$ \\
\hline 2018 & $\begin{array}{l}29 \% \quad(8 \\
\text { municipios) }\end{array}$ & $\begin{array}{l}68 \% \quad(19 \\
\text { municipios) }\end{array}$ & - & - & - & $\begin{array}{l}3 \% \quad(1 \\
\text { municipio) }\end{array}$ & $\begin{array}{l}100 \% \quad(28 \\
\text { municipios) }\end{array}$ \\
\hline
\end{tabular}

Fuente: Elaboración propia

\section{Gráfico $\mathrm{N}^{\circ} 2$}

Redes partidarias del Frente Cívico electas en los municipios de la provincia. Expresada en porcentajes

\section{redes partidarias del Frente Cívico electas en los municipios de la provincia. Expresada en porcentaje}

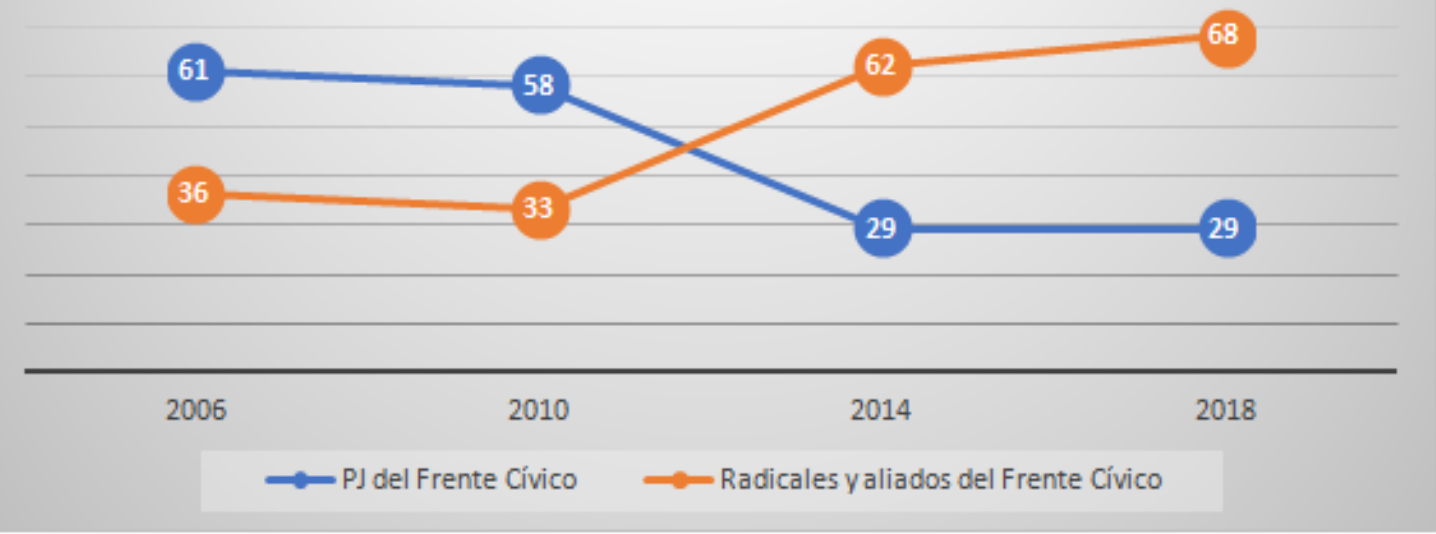

Fuente: Elaboración propia

\section{División sexual del trabajo político}

En relación al género del intendente electo, es claro el dominio de los hombres en la política local que se ve reflejado en la cantidad de intendentes hombres y mujeres electos. De los 26 intendentes electos de agosto de 2018, y sumando a los 2 del año 2017, solo 3 son mujeres y pertenecen al Frente Cívico. Aparte de Marcela Mansilla, intendenta de Colonia Dora, se encuentra la peronista Estela Protti, de la localidad de Suncho Corral, y la ingeniera Norma Fuentes, intendenta electa de la ciudad capital. 
Norma Fuentes es la primera mujer electa para ser intendenta de la capital, la ciudad principal de la provincia. Ingeniera vial de profesión, militante del radicalismo en la ciudad, y durante los últimos años ejerció como Ministra del Agua provincial, con destacada labor en la gestión.

"Norma tiene un perfil distinto. Es una mujer muy formada, que se destacó en su trabajo. Qué no está como candidata o futura intendenta electa por rosca política solamente o por movilizar, sino que se lo ganó porque es una máquina de trabajar" (Entrevista a secretaria de Fuentes, una semana antes de las elecciones).

\section{Cuadro $\mathrm{N}^{\circ} 2$}

Intendentes de la Provincia de Santiago del Estero según género (2006-2018)

\begin{tabular}{|l|l|l|l|l|}
\hline & 2006 & 2010 & 2014 & 2018 \\
\hline $\begin{array}{l}\text { Intendentes } \\
\text { Hombres }\end{array}$ & $93 \%$ & $93 \%$ & $93 \%$ & $89 \%$ \\
\hline $\begin{array}{l}\text { Intendentes } \\
\text { Mujeres }\end{array}$ & $7 \%$ & $7 \%$ & $7 \%$ & $11 \%$ \\
\hline Total & $100 \%$ & $100 \%$ & $100 \%$ & $100 \%$ \\
\hline
\end{tabular}

Fuente: Elaboración propia

\section{Categorías socioprofesionales de los intendentes electos}

Las categorías socioprofesionales permiten un acercamiento a la composición sociológica de los intendentes electos y advertir los mundos sociales de pertenencia (Vommaro, 2017). Ellas proporcionan un acercamiento a la socialización y formación de los políticos y revelan las variaciones observables en el reclutamiento de los mismos. El trabajo con prosopografía resulta útil para examinar la morfología de los actores políticos y sus canales de acceso para sus intendencias. ${ }^{16}$

En relación a los oficios, ocupaciones y profesiones de los intendentes pudimos clasificarlos en 5 tipologías: 1) empresarios, principalmente vinculados a los agro negocios, ganadería y forestal; 2) profesiones liberales, como abogados, médicos, odontólogos y contadores; 3) empleados municipales o trabajadores políticos dentro de las estructuras partidarias con vínculo en sectores populares; 4) profesores en las escuelas o colegios que otorga capital social dentro de los municipios de tercera categoría; 5) religiosos, ex sacerdotes que se volcaron a la política municipal.

La importancia de conocer los oficios, ocupaciones y profesiones de los intendentes nos ayuda a identificar los capitales sociales de origen que luego se reconvierten en capital político, es decir en capital simbólico y legítimo para disputar la autoridad política local. Vale aclarar que la presentación de los oficios, ocupaciones y profesiones de los intendentes no pretende explicar por 
sí solo el triunfo o la derrota electoral, pero puede aportar a la comprensión de continuidades y rupturas en la construcción de liderazgos locales.

Mientras que hasta el año 2010 primaban intendentes que venían de acumular capital social como empleados municipales, profesionales de la política partidaria, ex sacerdotes, la mayoría vinculados al peronismo, en el 2014 emerge una transformación relativa: la mayoría de los intendentes electos de la facción radical y aliados provienen de clases sociales medias o medias altas con profesiones liberales o empresarias.

\section{Cuadro $\mathrm{N}^{\circ} 3$}

Oficios, ocupaciones y profesiones de los intendentes electos 2006- 2014 según tipología construidas

\begin{tabular}{|c|c|c|c|c|c|c|}
\hline & $\begin{array}{l}\text { Empresarios, } \\
\text { principalmente } \\
\text { vinculados a } \\
\text { los agro } \\
\text { negocios, } \\
\text { ganadería y } \\
\text { forestal }\end{array}$ & $\begin{array}{l}\text { Profesiones } \\
\text { liberales, } \\
\text { como } \\
\text { abogados, } \\
\text { médicos, } \\
\text { odontólogos } \\
\text { y } \\
\text { contadores }\end{array}$ & $\begin{array}{l}\text { Empleados } \\
\text { municipales } \\
\text { o } \\
\text { trabajadores } \\
\text { políticos } \\
\text { dentro de } \\
\text { las } \\
\text { estructuras } \\
\text { partidarias }\end{array}$ & $\begin{array}{l}\text { Profesores } \\
\text { en las } \\
\text { escuelas o } \\
\text { colegios }\end{array}$ & $\begin{array}{l}\text { Ex } \\
\text { sacerdotes }\end{array}$ & Total \\
\hline 2006 & $21 \%$ & $21 \%$ & $30 \%$ & $21 \%$ & $7 \%$ & $100 \%$ \\
\hline 2010 & $25 \%$ & $32 \%$ & $21 \%$ & $14 \%$ & $8 \%$ & $100 \%$ \\
\hline 2014 & $47 \%$ & $36 \%$ & $11 \%$ & $6 \%$ & $0 \%$ & $100 \%$ \\
\hline 2018 & $47 \%$ & $38 \%$ & $9 \%$ & $6 \%$ & $0 \%$ & $100 \%$ \\
\hline
\end{tabular}

Fuente: elaboración propia en base a matrices

\section{A modo de cierre}

Las perspectivas socio culturales de la política se refieren a investigaciones que buscan conocer las formas partidarias en relación con el mundo socio cultural que las contiene. En ese sentido, los conceptos trabajados en el artículo contribuyen a prestar atención a los anclajes sociales que proveen marcos de sentido, a la vez condicionamientos y recursos para la acción de los actores políticos.

$\mathrm{Al}$ referirnos a anclajes sociales no queremos dar cuenta de una suerte de determinismo social de la vida política, sino identificar conexiones sociales y complicidades culturales que la constituyen, y que solo pueden conocerse si se abandonan las miradas centradas en instituciones políticas o en sistemas cerrados sobre sí mismos (Vommaro, 2017). El desafío es indagar la vida política más allá de los incentivos racionales de la acción, para interesarnos por las prácticas políticas y los entornos implicados en su construcción de jerarquías. 
La sociología política construye el centro de análisis en las prácticas sociales, estudiando la política como proceso y relaciones. El artículo pretendió: 1Repensar los estudios sobre partidos en Argentina, caracterizados por centralidad de los líderes e importancia de la vida informal de los partidos; dependencia de los recursos del Estado y enraizamiento social en su funcionamiento cotidiano (Vommaro y Armesto, 2015, p. 116); 2-Rescatando un sentido multiescalar de la sociología política, los estudios políticos electorales ayudan a pensar que lo provincial es un espacio de producción de lo político.

Las tensiones del Frente Cívico y del mismo sistema político provincial, la consolidación del cambio de gobiernos municipales y la pérdida de organización territorial del PJ Frente Cívico, respondió principalmente a dos elementos: el agotamiento de las redes políticas que gobernaban los municipios con varios mandatos consecutivos, y al crecimiento de las redes "conducidas" por dirigentes de origen radical en los años de gobierno provincial del Frente Cívico. El agotamiento de las gestiones municipales peronistas respondió a la presencia de una alternativa local, que también representa al oficialismo provincial y que generó posibilidades de organización territorial y de expansión de las redes de sociabilidad e intercambio para disputar electoralmente a las redes del peronismo.

Por último, poner en valor que los estudios de los mundos sociales de pertenencia de las redes partidarias dan luz a las formas de sociabilidad y prácticas (formas de organización territorial) a través de las cuales los actores políticos adquieren esquemas interpretativos y expresivos, saberes prácticos y repertorios de acción.

\section{Referencias}

Abdulhadi, A. (2016). Disputas faccionales y cortes judiciales en las provincias argentinas: Misiones bajo el Frente Renovador (2003-2011). Revista SAAP: Sociedad Argentina de Análisis Político, 10(2), 355-374.

Calvo, E. y Escolar, M. (2005). La nueva política de partidos en Argentina: crisis politica, realineamientos partidarios y reforma electoral. Buenos Aires: PENT/Prometeo.

Campos, H. (2021). Redes politicas y elecciones en Santiago del Estero: las formas de organización territorial del Frente Civico 2005-2018. Santiago del Estero: Edunse.

Campos, H. (2018). Las formas de organización territorial y articulaciones politicas en Santiago del Estero durante el kirchnerismo (2005-2013). (Tesis Doctoral). Centro de Estudios Avanzados de la Facultad de Ciencias Sociales de la Universidad Nacional de Córdoba.

Campos, H. y Schnyder, C. (2016). Transformaciones y continuidades de la política popular en Santiago del Estero: las formas de organización territorial del Partido Justicialista Juarista y de las organizaciones kirchneristas. Revista Cuadernos FHyCS UNJu, 50, 13-33.

Campos, H. (2014). La constitución del partido y del frente electoral Compromiso Social dentro de las condiciones de posibilidad del régimen político de Santiago del Estero. Revista Trabajo y Sociedad, 23, 287-306.

Frederic, S. (2004). Buenos vecinos, malospoliticos: moralidady politica en el Gran Buenos Aires. Buenos Aires: Prometeo. 
Hurtado Arroba, E., Paladino, M. y Vommaro, G. (2018). Las dimensiones del trabajo político: destrezas, escalas, recursos y trayectorias. Íconos, Revista de Ciencias Sociales, 60, 11-29.

Landau, M. (2019). Jerarquías sociales y políticas. Un estudio en Buenos Aires y Santa Fe". Estudios Sociológicos. 37 (109), 69-98.

Leiras, M. (2007). Todos los caballos del rey. La integración de los partidos politicos y el gobierno democrático de la Argentina, 1995-2003. Buenos Aires: Prometeo.

Maidana, M. F. (2016). Los cholos y los negros. Sustitución de elites dirigenciales en el Partido Justicialista de Salta (P.J.) en los años 1995 a 2011. PolHis. Revista Bibliográfica Del Programa Interuniversitario De Historia Politica, 17, 276-312.

Merklen, D. (2005). Pobres ciudadanos. Las clases populares en la era democrática (Argentina, 1983-2003). Buenos Aires: Ed. Gorla.

Offerlé, M. (2011). Perimetros de lo político: contribuciones a una socio historia de la política. Buenos Aires: Antropofagia.

Ortiz De Rozas, V. (2014). Dirigentes representativos y capital territorial. Los partidos provinciales a través del estudio de los capitales politicos de los líderes intermedios. Santiago del Estero (1999-2013). (Tesis Doctoral). Universidad de Buenos Aires.

Quilici, F. (2017). Diseños institucionales multinivel y desnacionalización política. el surgimiento del frente renovador en misiones. Revista POSTData: Revista de Reflexión y Análisis Politico, 22(2), 395-436.

Sawicki, F. (2020). Los partidos como empresas culturales. En F. Lorenc Valcarse y G. Vommaro, (comp.). La politica en plural: Investigaciones sociales sobre la politica contemporánea. Mar del Plata: EUDEM.

Sawicki, F. (2011). Para una sociología de los entornos y de las redes partidistas. Revista de Sociologia de la Universidad Nacional de Chile, 25, 37- 53.

Schnyder, C. (2013). Politica y Violencia. Santiago del Estero 1995-2004. Santiago del Estero: EDUNSE.

Schnyder, C. y Rea, P. (2007). Alcances de la transformación de los partidos en Santiago del Estero. El caso del Frente Cívico por Santiago en el proceso electoral 2005-2007. Sexta Reunión de la Red Nacional sobre Procesos Electorales, Instituciones Politicas y Ciudadanía. Buenos Aires: Instituto de Investigaciones Gino Germani. 29 de agosto de 2007.

Silveti, M. I. (2006). Alianza entre dirigentes y apatía ciudadana en Santiago del Estero. En Cheresky, I. (Comp.). La politica después de los partidos. Buenos Aires: Prometeo, 305-330.

Silveti, M. I. (2012). Argentina: los actos comiciales en Santiago del Estero entre 2001 y 2009: Una metodología para el estudio de las prácticas partidarias y ciudadanas. Revista Espacio Abierto Cuaderno Venezolano de Sociología, 21, 227-245.

Soprano, G. (2008). Doña Silvia. Análisis de redes políticas en el peronismo de la provincia de Misiones durante una campaña electoral municipal. Andes. Antropología e Historia, 19, 119-155.

Vaca Ávila, P. (2017). "Estrategias de permanencia en sistemas subnacionales de partido predominante. El caso de Jujuy (1983-1999)”. Sudamérica, 6, 14-41.

Vommaro, G. y Gené M. (2017). La vida social del mundo politico. Investigaciones recientes en sociología politica. Ediciones UNGS: Los polvorines.

Vommaro, G. (2018). Reflexiones a partir de una experiencia de investigación en sociología política. Prácticas de oficio, 20, 30-39.

Vommaro, G. (2017). Los partidos y sus mundos sociales de pertenencia: repertorios de acción, moralidad y jerarquías culturales en la vida política. En Vommaro, G. 
y Gené M. (comp). La vida social del mundo politico. Investigaciones recientes en sociología politica. Ediciones UNGS: Los polvorines.

Vommaro, G. y Morresi, S. (2016). Introducción. El PRO como laboratorio político. Aprehender un partido a partir de los espacios y las temporalidades de su construcción. En Vommaro y Morresi (comp.). Hagamos Equipo. PRO y la construcción de la nueva derecha en Argentina. Ediciones UNGS: Los polvorines.

Vommaro, G. (2016). Capítulo 3. Contribución a una sociología política de los partidos. Los mundos sociales de pertenencia y las generaciones políticas de PRO. En Vommaro y Morresi (comp.). Hagamos Equipo. PRO y la construcción de la nueva derecha en Argentina. Ediciones UNGS: Los polvorines.

Vommaro, G. y Armesto, M. (2015). ¿Nuevos políticos en el partido, viejos políticos en las listas? Reclutamiento partidario y división del trabajo político en PRO, en la Ciudad Autónoma de Buenos Aires. Revista Pasado Abierto. CEHis - UNMDP, 1 (2), 110-132.

Vommaro, G. (2009). Redes políticas y redes territoriales en la construcción del posjuarismo. En Silveti (Comp.). El protector ilustre y su régimen: redes politicas y protesta en el ocaso del juarismo. Santiago del Estero: Ed. INDES.

Vommaro, G. (2004). La política santiagueña en las postrimerías del juarismo. Elecciones nacionales, provinciales y municipales, septiembre 2002/septiembre 2003. En I. Cheresky y I. Pousadela (eds.). El voto liberado. Elecciones 2003: perspectiva histórica y estudio de casos. Buenos Aires: Editorial Biblos.

Vommaro, G. (2003). Partidos partidos: elecciones y política en Santiago del Estero 1999-2001. En I. Cheresky; J. Blanquer (comps.). De la ilusión reformista al desencanto ciudadano. Rosario: Homo Sapiens.

Vommaro, G. y Quirós, J. (2011). “Usted vino por su propia decisión”: repensar el clientelismo en clave etnográfica. Revista Desacatos, 36, 65-84.

\section{Notas}

1 En la bibliografía nos encontramos con los aportes de Frederic (2004), que investigó, en un municipio de la provincia de Buenos Aires, cómo se reconstruyen lógicas sociales, las formas de ejercicio concreto del poder y la autoridad, del simbolismo de las prácticas y dimensionó el peso de los valores tomando como eje a los actores sociales locales como intendentes, militantes, vecinos, etc. También ponemos en valor el texto de Soprano (2008), que analizó, desde la antropología, redes políticas en el peronismo de la provincia de Misiones durante una campaña electoral municipal.

2 Según datos del CENSO 2010, Santiago del Estero posee 874.006 habitantes, con una proyección de 968.309 para el año 2019 (esto representa el 2,18\% de la población nacional). Los departamentos con mayor concentración de población son el departamento Capital, Banda y Río Hondo (acaparando el 53\% del total provincial). Los mayores núcleos poblados son la conurbación Santiago del EsteroLa Banda, con cerca de 400.000 habitantes, seguida por Termas de Río Hondo, Frías y Añatuya, ciudades de entre 20.000 y 30.000 habitantes, y por último Fernández, Monte Quemado, Quimilí y Clodomira de entre 10.000 y 15.000 habitantes. En el plano político-administrativo, la provincia se encuentra dividida en 27 departamentos: Aguirre, Alberdi, Atamisqui, Avellaneda, Banda, Belgrano, Juan Francisco Borges (Capital), Copo, Choya, Figueroa, Guasayan, Ibarra, Jiménez, Loreto, Mitre, Moreno, Ojo de Agua, Pellegrini, Quebrachos, Río Hondo, Rivadavia, Robles, Salavina, San Martín, Sarmiento, Silípica y Taboada. Cada uno de estos cuenta con una localidad cabecera. Entre ellas se destaca la ciudad de Santiago del Estero como la capital de la provincia. 
3 Permite mostrar cómo los actores políticos, redes, partidos y/o frentes acumulan recursos de poder de un modo situado, con dinámicas propias y en relación con el nivel provincial y nacional.

4 Se trabajó con entrevistas, registros de observación y trabajo de archivo en diarios provinciales.

5 Los municipios de Ojo de Agua, Selva, Nueva Esperanza, Monte Quemado, Campo Gallo, San Pedro de Guasayan, Sumampa, Quimilí, Loreto, Fernández, Beltrán, Suncho Corral, Colonia Dora, Bandera, Frías, Termas de Rio Hondo, La Banda y Santiago Capital, fueron los municipios donde se realizaron entrevistas y registro de observaciones en las elecciones 2014 y 2018.

6 "Sawicki propuso combinar las perspectivas que denomina societales- y que engloban las ideológicas y las sociológicas- con las organizacionales a partir de dos movimientos análitico-metodológicos. Por un lado, entender los partidos como redes, es decir pensarlos organizativamente a partir de esta metáfora que permite aprehender las diferentes instancias, formales e informales, de existencia que, en conjunto, aunque a veces sin proponérselo, le dan vida interna. Por el otro, estudiar estas redes en sus relaciones con lo que el autor llama el "entorno partidario", es decir, las redes relacionales que se entrecruzan, que están basadas en valores e intereses compartidos, y son "alimentadas mediante interacciones en diversos lugares de sociabilidad más o menos formales: asociaciones, sindicatos, cooperativas, mutuales, cafés" (Sawicki, 2011, p. 43)" (Vommaro y Morresi, 2016, p.18)

7 “(...) agregamos una dimensión más a la noción de entornos partidarios, la del modo en que esa complicidad cultural nutre al partido de elementos que conforman su ethos político, es decir, su repertorio dominante de prácticas, visiones del mundo y formas de dar cuenta de él en discursos y presentaciones públicas" (Vommaro, 2017, pp. 42-43).

8 Para leer sobre el trabajo político en el Juarismo, se tiene el texto de Schnyder (2013). Sobre el concepto de trabajo político revisar a Hurtado Arroba, Paladino y Vommaro (2018) y Vommaro y Quirós (2011).

9 Desde la recuperación de la democracia en 1983, los oficialismos provinciales nunca perdieron una elección. En 1983, Carlos Juárez ganó la elección a Gobernador con el Partido Justicialista. En las elecciones provinciales de 1987, Iturre, candidato peronista, ganó con el apoyo de Juárez y presentándose como leal a la conducción juarista. Una vez en el gobierno, Iturre se diferenció de Juárez y creó su propio partido político "La Corriente Renovadora”. En las elecciones para gobernador de 1991, la Corriente Renovadora ganó siendo oficialismo. La situación de crisis económica nacional, durante el ajuste neoliberal del menemato, hizo que se desplace hacia la política y sus instituciones. La corriente renovadora se imponía en las urnas, pero las movilizaciones populares en contra del ajuste condenaron al partido. El descalabro social llevó a la Intervención Federal de Diciembre de 1993, y a la designación del dirigente peronista cordobés Schiaretti como su interventor. En las elecciones de 1995, volvió Carlos Juárez y el Partido Justicialista a la gobernación. Desde esa elección de 1995 y las tres elecciones que le continuaron hasta la Intervención Federal de Abril de 2004, nunca perdió el Juarismo siendo oficialismo. La última Intervención Federal, que en el presente trabajo será descripta con mayor detalle, significó el final del juarismo y la condición para el surgimiento del Frente Cívico, fuerza política que continúa en el gobierno. Para profundizar lecturas se recomienda visitar el texto de Campos y Schnyder (2016).

10 Claudia Ledesma, es abogada y escribana; de extracción y militancia radical durante su juventud en La Banda, su ciudad natal; fue electa en el 2003 como Defensora del Pueblo de la Banda hasta el 2005.

11 "En 2013 la Corte Suprema de Justicia impugnó una nueva candidatura de Zamora para la gobernación, en tanto violaba la disposición de la Constitución provincial reformada en 2005, que limitaba la posibilidad de reelección a un período. Su mujer, Claudia Ledesma Abdala, fue finalmente propuesta para la candidatura, resultando electa con el $64,3 \%$ de los votos, reduciendo el caudal electoral de su marido, pero manteniendo una amplia brecha electoral con los opositores - a quienes aventajó por una diferencia de 49 puntos porcentuales" (Ortiz de Rozas, 2014, p. 17).

12 Como suplente estaba Gerardo Zamora. Finalmente, asumirá la banca en lugar de Brue. 
13 Montenegro es secretario adjunto de la Confederación General de Trabajadores (CGT) y del gremio Unión del Personal Civil de la Nación (UCPN); con trayectoria dentro de la militancia juarista.

14 Para profundizar lecturas sobre diferentes procesos electorales en la provincia, se recomienda leer los textos de Silveti, 2012; Silveti, 2006; Campos, 2014; Schnyder y Rea, 2007; Vommaro, 2009.

15 Las restantes son Norma Fuentes en la ciudad capital y Estela Protti en Suncho Corral.

16 Michel Offerlé (2011) esboza dos enfoques posibles para analizar la profesión política. Por un lado, una mirada que hace hincapié en la composición sociológica de los elencos políticos, el cual centra su análisis en el examen de las profesiones previas como manera de acceder a los canales de reclutamiento, las profesiones más proclives a vivir "de" la política y a la extracción social de los grupos dirigentes. Una segunda mirada privilegia el estado "actual" de los políticos profesionales donde se centra la mirada en la especificidad de la actividad política como tal, desencastrada de su relación con lo social. Este enfoque privilegia la actividad política como una actividad autónoma, donde los roles y reglas son propios del universo político. Esta segunda mirada daría menor importancia al análisis de las categorías profesionales. 